\title{
La función de la universidad en el pensamiento de Ignacio Ellacuría Una visión desde nuestro contexto actual
}

\author{
Juan Antonio Senent de Frutos*
}

\section{Introducción}

Quiero agradecer la invitación al Forum Deusto de la Universidad de Deusto', a Javier Elzo y a la Provincia de Loyola de la Compañía de Jesús, por recoger el testigo que nos legó Ignacio Ellacuría con esta iniciativa: "Ignacio Ellacuría y compañeros mártires de El Salvador: Constructores de una cultura para la justicia".

Y quiero tomar como problema de partida de esta conferencia sobre la función de la universidad en el pensamiento de Ellacuría el lema de las actividades en la que se enmarcan estas conferencias. Ellacuría, cuando hablaba o escribía, no se quedaba en una aproximación del tema superficial o puramente académica. Le interesaba ir al fondo y al sentido de la cuestión que se debatía.

* Profesor del Departamento de Filosofía del Derecho de la Universidad de Sevilla y del Programa de Máster y Doctorado de Derechos Humanos, Interculturalidad y Desarrollo de la Universidad Pablo de Olavide de Sevilla, desde 1998. Profesor invitado en la UCA de El Salvador y en otras universidades latinoamericanas. Entre sus publicaciones destacan Ellacuría y los derechos humanos, Bilbao, 1998; y Problemas fundamentales de los derechos humanos en el horizonte de la praxis, Valencia, 2007. Ha colaborado con autores como Enrique Dussel, Franz J. Hinkelammert, Boaventura de Sousa Santos o Raúl Fornet-Betancourt en la edición de diversos libros en la línea del pensamiento de la liberación latinoamericano y la teoría crítica. Patrono de la Fundación Francisco Suárez de la Compañía de Jesús en Andalucía y Canarias.

1. Este escrito tiene su origen en la conferencia impartida con el mismo título en noviembre de 2009 en la Universidad de Deusto, y tuvo su última revisión en noviembre de 2010. 
También procuraba siempre historizar y contextualizar el tema para que este diera de sí lo que debía. En esta misma línea, nos interesa traer su pensamiento y proyectarlo para enfrentar los desafíos actuales que tiene planteada la misión de la universidad. La idea central de Ellacuría ya está preanunciada en el lema: construir una cultura de la justicia. O dicho con el lenguaje de su época, la función de la universidad es contribuir desde su propia especificidad a la liberación de la sociedad. Además, nos habla del martirio, de la vida arrebatada en la lucha por la justicia. Si a Ellacuría lo mataron como rector y como universitario, fue porque su actividad no fue meramente contempladora y cognoscente de la realidad social, y, por tanto, distante y a salvo del objeto del conocimiento. En su tarea, puso en juego su vida no por alcanzar una mera "verdad objetiva" y por su comunicación, sino por su compromiso vital e institucional con la realidad social para que diera de sí lo que podía y debía: una sociedad justa, superadora de una sociedad rota e inviable por la presencia masiva del mal y de la muerte.

Pero este planteamiento, y este proyecto de misión universitaria, tenía no solo que enfrentarse a los poderes que respaldaban la continuidad de ese mal, sino también tenía un fuerte carácter contracultural. Lo que a nosotros nos parece hoy evidente en el caso de la UCA o de Ellacuría, a fuerza de conocer esa historia concreta, no era entonces evidente, ni lo es hoy en el contexto de la universidad actual. La misión de la universidad en la sociedad moderna, podríamos decir de su "tipo ideal", se centra en la producción de un conocimiento social y naturalmente aplicable y en la educación superior de las élites profesionales de esa sociedad ${ }^{2}$. La lucha por la justicia o por la mejora de la sociedad no es objeto preferente de la acción universitaria, sino que este es fundamentalmente

2. Así, por ejemplo, Ortega y Gasset, en su clásico ensayo La misión de la universidad (1930), señala que esta consiste en educación técnica superior o especializada e investigación científica; junto a estas dos funciones principales, rescata un "residuo", que era central en la universidad medieval y que pervive marginalmente en la universidad moderna: la formación en "cultura general". Esa "cultura" no como ornamento erudito, sino como transmisión del sistema de ideas sobre el mundo que a la altura de su momento histórico vivifican el dinamismo social, y cuya adquisición personal permitiría la orientación vital del sujeto en el caos confuso de la "selva salvaje" de la vida ( $C f$. "La misión de la Universidad", en Obras completas de José Ortega y Gasset, 4. ${ }^{\text {a }}$ ed., Revista de Occidente, 1957, pp. 320 y ss.). Sin embargo, en la concepción orteguiana subsiste la función puramente transmisora y reproductora del sistema de ideas o del proceso de racionalización del mundo humano y no humano. Es decir, la misión universitaria no deja de ser ilustración a la altura de su tiempo. Todo ello, aun siendo valioso y un suelo del que partir, no le imprime una tarea ética propia, pues no hay una pregunta fundamental por la "racionalidad de lo racionalizado", y, por tanto, el cuestionamiento de los límites de las ideas vigentes en tanto que se revelen insuficientes, contradictorias o nihilistas para la marcha personal, social y natural. 
la formación de una sociedad ilustrada y desmitologizada. Por tanto, la única liberación que puede ofrecer la universidad en la modernidad se centraría en el acceso al conocimiento objetivo que nos procuran las diversas ciencias empíricas que se cultivan en ella. No es misión universitaria contribuir a una orientación racional de la ética individual ni social, lo que se considera un campo exclusivo de las ideologías y cosmovisiones particulares de los diversos miembros, y por tanto de una lucha inacabable e indiscernible entre valores, dada la ausencia de objetividad o la pura subjetividad de los valores y fines humanos, como suele plantearse en este campo, desde la hegemónica mentalidad no cognoscitivista. En el proceso de transformación de la universidad en la sociedad moderna, y que culmina en los siglos XIX y XX, se produjo una crisis y un desplazamiento de la metafísica, de la teología y de la ética, como asuntos, si se quiere, privados e indiscernibles y dependientes únicamente de opciones individuales o sociales, y que en su caso serán tomadas como disciplinas y objetos de estudio, pero en último término desvinculadas de la misión universitaria como tal. Tampoco debía ofrecer un autocuestionamiento del canon asumido de racionalidad, una radicalización crítica de los límites de un conocimiento objetivo desvinculado del mundo en el que opera, para ofrecer otros modos racionales de estar en la realidad.

Y bien, decía que hay un problema de partida. El modelo de universidad de Ellacuría no encaja en el modelo tradicional, ni encaja el modo de ejercer la racionalidad que propuso y vivió. Pero entonces, se plantea una pregunta seria: ¿tiene algo que ofrecer en el mundo de hoy o es una simple concepción particular, conmovedora si se quiere, al estilo de las "historias tristes" de las que hablaba Richard Rorty ${ }^{3}$, y que genera, por su sentimentalidad, una cierta simpatía solidaria, pero sin más razón, pública y frente a cualquiera?; ¿tenemos razones para decidirnos por un modelo de universidad que incida en el conjunto de la realidad social y que ofrezca racionalmente una orientación ética a la sociedad, o que genere otro modelo cultural para el desarrollo social? Esa es la pregunta que voy a tratar de enfrentar en esta conferencia.

Para ello, la articularé en dos partes principales; en la primera, trataré de recoger el modelo de racionalidad desplegado en la historia moderna de la universidad, en el contexto del mundo producido por la modernidad; y en la segunda, abordaré la propuesta ellacuriana, su posible racionalidad y la fuente de su alternativa cultural.

\section{Modelo de racionalidad universitaria en la modernidad}

Trataré el tema de modo sintético, buscando el esquema del proceso histórico vivido desde nuestra altura procesual.

3. R. Rorty, "Derechos humanos y sentimentalidad", en S. Shute y S. Hurley (eds.), De los derechos humanos. Las conferencias de Oxford Amnesty de 1993, Madrid, 1998. 
Si hablamos de racionalidad universitaria moderna, en realidad no estamos postulando una racionalidad distinta de la vivida en la sociedad. En cierto modo, en la universidad se da, como en otros espacios, una autoconciencia de la normatividad de la racionalidad que hegemónicamente se impuso en el desarrollo social y que fue desplazando progresivamente a la marginalidad cultural a otras racionalidades de la época medieval. Pero se trata de una institución que es un instrumento donde se cultiva la racionalidad moderna en el campo de las ciencias y de su transmisión social. Ese instrumento será regido, por tanto, por el modelo de racionalidad de la sociedad, y, a su vez, será vector de su propio despliegue.

La modernidad, que arranca en el Renacimiento y que se hace más visible desde la Ilustración, tiene, como sabemos, un carácter antropocéntrico, entendido este como centramiento en la realidad humana que se erige en lugar de la verdad, y en último extremo como realidad por antonomasia. Desde sí mismo, el individuo, o en su caso la sociedad, tiene que construir y proyectar su vida libremente, y también proyectar esa libertad frente al mundo natural al que tratará de someter a sus deseos y necesidades. En este sentido, toda otra realidad es vista desde un marco humano que experimenta su realidad como algo contradistinto al mundo, a los otros y a Dios. Desde este giro antropocéntrico, mediado principalmente por una lógica individualista y culturalmente etnocéntrica ${ }^{4}$, se pretende la autoafirmación de la razón humana y social que no se somete a otras instancias. El proyecto moderno de la razón pretende alcanzar lo que Kant denominó la superación de un estado de minoría de edad, pero termina incurriendo en una cierta pretensión de omnipotencia en la mayoría de edad. En este sentido, con la emergencia de la subjetividad moderna, la razón se hace razón subjetiva, como señalara Max Horkheimer ${ }^{5}$. Se libera así de otras fuentes de normatividad ${ }^{6}$ o

4. La historia del etnocentrismo es larga en la modernidad. Se articuló, en cuanto a su exterioridad, en el proceso de colonización del mundo no occidental. Traeré aquí simplemente el recuerdo de un autor decisivo para la constitución de nuestra cultura ético-política, John Locke. Desde su obra se ha tratado de fundamentar la democracia liberal, la idea de la universalidad de los derechos humanos, o la tolerancia y la libertad religiosa en una perspectiva ilustrada. Sin embargo, hay en sus obras fuertes negaciones del humanismo racional y universalista defendido, en particular para los que no pertenecen a la civilización europea o pretenden otro desarrollo cultural de la misma civilización europea. La cuestión del etnocentrismo lockeano la he abordado en "La tierra y la naturaleza en el horizonte de la subjetividad moderna", en Die Bedeutung der Erde in den Kulturen. Zum Dialog der Kosmologien vor der ökologishen Herausforderung. Dokumentation des XIII. Internationalen Seminars des Dialogprogramms Nord-Süd, Mainz, 2009, pp. 168-179.

5. M. Horkheimer, Zur Kritik der instrumentellen Vernunf (trad. de J. Muñoz, Crítica de la razón instrumental, Madrid, 2002).

6. El saber en tanto que humano en el contexto de modernidad (tanto en sus dimensiones teóricas como prácticas), llega a señalar Hans Blumenberg, en el fondo no 
de autoridad, provenientes de Dios, la religión, las tradiciones culturales o del propio mundo natural; son instancias a-racionales, es decir, que no tienen validez racional o relevancia para el propio ejercicio racional del sujeto, y en este sentido estarían más allá de su racionalidad, cuando no resulten simplemente irracionales y por tanto tengan que ser combatidas, dominadas o reemplazadas. Pero incluso en el caso de la racionalidad ejercida socialmente en el campo político, este no se hace inter-subjetivo en un sentido pleno (como pretende la ampliación última de la razón moderna intersubjetiva); sino que funciona como un cuerpo social único. Es decir, la legitimación de las normas, los fines a perseguir o los valores, se da en un marco de justificación autocentrado, donde no intervienen otras alteridades, ni tampoco los otros que quedan fuera del cuerpo político que se autodetermina. En este sentido, la soledad ontológica, que se va definiendo en el proyecto civilizatorio de la modernidad, al concentrarse en la subjetividad humana, conduce como necesidad a una soledad ética, tanto de los individuos como de los cuerpos sociales. Esto hará que las decisiones prácticas, las jurídicas, morales o políticas no puedan ni necesiten justificarse frente a las otras alteridades con las que se desenvuelve la subjetividad, su cuerpo, la naturaleza, los otros que están más allá y más acá del cuerpo social, en tanto que no se aborda un criterio material de corrección.

Pero no se trata solo de una estrategia de autoconstitución, sino a la par de progresiva desvinculación. Como sintetiza Xavier Zubiri, partiendo del eco que en la obra cartesiana tiene la modernidad emergente, "el hombre (no) es un trozo del universo, una cosa que está ahí (...) Descartes corta el vínculo que une el saber a lo que el hombre es y convierte al saber en el ser mismo del hombre"7. En esta línea, el sujeto ya no es un trozo del universo, sino que es algo en cuyo conocimiento va contenido todo el universo. Por ello, el sujeto ya no es polvo del universo, sino "envolvente del mismo".

En el proceso de extrañamiento ante el mundo, lo real pierde su contextura, sus límites, parece convertirse en "espacio vacío". El sujeto no pertenece ni está imbricado en el mundo, y además está solo. Su verdad y su realidad individual no están abiertas a los otros en un sentido fuerte ${ }^{9}$ para cualificar el grado de justicia

necesita justificación, pues "se justifica a sí mismo; no se debe a Dios, no tiene nada que ver con la iluminación y la participación por medio de la gracia, sino que reposa en su propia evidencia, a la que Dios y el ser humano no se pueden sustraer" (La legitimación en la Edad Moderna, Valencia, 2008, p. 395).

7. X. Zubiri, Naturaleza, historia y Dios, 1994, p. 285.

8. I. Ellacuría, "La idea de filosofía de X. Zubiri", en Homenaje a X. Zubiri, Madrid, 1970, p. 583.

9. Es cierto que el criterio de corrección universal es un legado permanente de la ética ilustrada desde Kant, que tuvo decisivas consecuencias para la fundamentación racional del derecho y la política en la modernidad, pero hay que tener en cuenta que 
o de bondad de su realización. Ello libera como última instancia la voluntad de poder o la lucha a muerte por la autoafirmación. Desde esta racionalidad, ¿cómo se orienta el sujeto en su realización?

Para ver esta cuestión es, a mi juicio, pertinente acudir a la obra de Max Weber, quien expresa magistralmente (y asume rigurosamente) el modelo racional de este proceso cultural. Así, nos dirá que el sujeto se orienta por "juicios de valor"; que son de una validez subjetiva, desde un "para mí" de carácter solipsista, no abierto a una validez pública, es decir, no objetivable ni discernible. El conocimiento riguroso y crítico, "universitario", no puede dar cuenta de la asunción de un valor ${ }^{10}$. Lo que puede aportar es un conocimiento objetivo y técnico de los medios para alcanzar los valores asumidos por cada cual, o por la política privada, social o pública. La ciencia, y la universidad con ella, lo que suministraría es una clarificación sobre la realización fáctica de cualquier finalidad, que de suyo la vería como a-científica, como algo en cuya racionalidad no puede

ese juicio de universalidad es un juicio que se formula desde el tribunal de la razón del propio individuo (o del cuerpo social individualmente considerado) que en vista de una consideración puramente formal y abstracta de los otros puede dar-se como universal una norma meramente desde sí mismo.

10. Max Weber describe esta situación, usando su propia metáfora en este contexto, como una especie de "jaula de hierro" de la que, lamentablemente, no podemos ni sabemos salir. Perdimos la llave, o se destruyó el puente que unía el mundo empírico al de la racionalidad o valor del reino de los fines. Su conciencia ilustrada adquiere un carácter infeliz: "Por desgracia (sub. mío) no existe un puente que desde el análisis puramente empírico de la realidad efectuado con los instrumentos de la explicación causal conduzca a la confirmación o refutación de la 'validez' de cualquier juicio de valor" ("Roscher y Knies y los problemas lógicos de la escuela histórica de economía", en J. M. García Blanco [ed.], El problema de la racionalidad en las ciencias sociales, Madrid, 1985, p. 73). Los valores e intereses particulares a los que puede servir la praxis científica son sobrepuestos a la misma, porque estos tienen un carácter o entidad no discernible racionalmente. Por ello, la ciencia se mueve con un método racional en la aprehensión de objetividades, pero en un mundo humano que tiene un carácter finalmente a-racional. De ahí la radical desorientación, de la que, para Weber, no puede escapar el campo científico, con lo que el mundo humano y no humano deviene finalmente en sin-sentido y desfundamentado. Desde esta situación espiritual en la que se encuentra el científico, y desde él el universitario, es posible entender la afirmación de Ortega y Gasset, de que "el científico viene a ser el monje moderno" (Cf. La misión de la universidad, óp. cit., p. 337). En rigor, para ellos y el mundo moderno no cabría serlo ya de otro modo, aun cuando ello no permita por sí mismo superar el nihilismo de lo humano, como sabe Weber, pues la “tensión entre la esfera de los valores 'científicos' y la de la salvación religiosa es totalmente insoluble" ("La ciencia como vocación”, en F. Rubio [ed.], El político y el científico, Madrid, 2003, p. 230). 
entrar" ${ }^{11}$ En este sentido, la supuesta "racionalidad" del fin o valor perseguido le viene dada desde fuera y se declara "agnóstico" de los valores o fines elegidos. Por tanto, la universidad no puede tener una misión ética sustantiva desde su misma radicalidad racional. Para Weber, y a mi juicio da cuenta certeramente del límite donde juega la racionalidad de la universidad moderna, o se hace ciencia y transmisión, o se hace política social ${ }^{12}$; pero si se hace esta, entonces ya no se cultiva la ciencia sino la política. Así, pues, "la característica del conocimiento científico ha de buscarse en la validez 'objetiva' de sus resultados como verdad"13. Pero esta verdad sigue enmarcada en una cierta búsqueda de la adecuación entre el conocimiento y la cosa. Por tanto, tiene un carácter estático al pretender inscribirse en el mero plano de la facticidad o del mundo empírico, y de ahí la voluntad de separación de todo elemento normativo o valorativo de la praxis científica más allá de mera ética interna de la lógica científica o la defensa de ciertos valores epistémicos, esto es, del proceder científico que no se integra en una perspectiva ética mayor con las otras dimensiones de la vida humana, del propio sujeto o del contexto social y material donde se despliega su acción. En esta línea, esta verdad científica se mueve desde el supuesto de la desvinculación con el objeto del conocimiento, e incluso con otras dimensiones de su propia praxis vital; por eso, el científico o el universitario, desde su condición, pueden declararse finalmente irresponsables de la suerte de los otros y de la naturaleza, o de su propia actividad científica.

En esta línea, se pregunta Weber qué significa un proceder científico como el que se practica, por ejemplo, desde una revista de investigación, incluso en el campo más cercano a lo humano como es el de las ciencias sociales: "Desde una disciplina empírica [se] debe rechazar radicalmente (la opinión de que se puedan generar científicamente juicios de valor, ya que no es función de una ciencia de la experiencia investigar ideales y normas obligatorias para poder deducir de ahí alguna receta para la práctica)"14. Lo único que puede hacer es realizar un "análisis científico de los juicios de valor". ¿Qué significa esto? Ayudar a la autoclarificación del fin querido; establecer los medios para conseguir un fin dado; calcular su probabilidad de consecución; en función de ello, valorar indirectamente si el propio fin propuesto es racional en virtud de la respectiva

11. Se trata de un límite epistemológico que se fundamenta en la constatación (desde su marco cultural) de la limitación ontológica o cosmológica de lo real. El ser humano se mueve en el mundo empírico, pero el reino del espíritu (valores, fines, sentido) no está imbricado ni habita en él.

12. Cf. E. Terrén, "Las aulas desencantadas: Max Weber y la educación", Política y Sociedad, n. 21 (1996), pp. 133 y ss.

13. M. Weber, Die "Objektivität" sozialwissenschaftlicher und sozialpolitischer Erkenntnis (J. Abellán [ed.], La "objetividad" del conocimiento científico en la ciencia social y en la política social, Madrid, 2009, p. 66).

14. Ibíd., p. 69. 
situación concreta o si no tiene sentido en función de las circunstancias dadas; es decir, su racionalidad "externa" reside en su posibilidad de cumplimiento del fin perseguido, cualquiera que este sea. Además, en caso del eventual logro del fin intencionado, establecer las consecuencias que tendría la aplicación de los medios necesarios al fin propuesto, en términos de costes o sacrificios. Se trata, por tanto, de un "análisis crítico técnico", pero ya "no es tarea de la ciencia llevar a cabo esa deliberación hasta la toma de decisión, pues esta última es una tarea del hombre que quiere algo: este sopesa y elige entre valores de que se trate según su propia conciencia y su propia y personal concepción del mundo"'15. Así, pues, "si el sujeto que emite un juicio debe declararse partidario de esos últimos valores es una cuestión personal, la más personal de todas, es decir, es cuestión de voluntad y de su conciencia, no de un conocimiento empírico"16. Por eso, una "ciencia empírica no puede enseñar a nadie qué debe hacer, sino solo qué puede hacer y, en algunos casos, qué es lo que realmente quiere hacer"17.

Esta es la autoconciencia rigurosa que la actividad científica puede tener sin dejar de ser estrictamente científica o, si se quiere, universitaria. Por tanto, contempla el mundo empírico y las realizaciones de los demás con una cierta ilustración sobre lo que acontece o puede acontecer, pero con una rigurosa neutralidad que le exime aparentemente de cualquier responsabilidad, aunque esté acompañando la marcha de ese mundo "con los ojos abiertos" viendo lo que pasa.

Veamos ahora brevemente cómo se proyecta esa racionalidad frente al mundo en el que se despliega.

Esta relación de la razón moderna frente al mundo llegará a articularse finalmente como racionalidad estratégica o instrumental. Como antes apuntamos, Max Horkheimer da cuenta de este proceso de reducción de la razón a "razón subjetiva"18, en el fondo una razón desvinculada de los otros y de lo otro, de cualquier instancia objetivante externa y en la que se arraiga. Se trata de la paradoja constitutiva de la razón moderna, pues es un conocimiento sobre el mundo, pero que está más allá del mundo, y, por tanto, se puede llegar a creer no interdependiente de la marcha del mundo.

Max Weber, por su parte, da otra clave para entender esta racionalidad frente al mundo. En la modernidad culminaría una evolución cultural, en la línea de la

15. Ibíd., p. 72 .

16. Ibíd., p. 74.

17. Ibíd., p. 78.

18. "Medios y fines", en Crítica de la razón instrumental, óp. cit., pp. 45 y ss. Este autor señala con cierta perplejidad cómo, para él, en el último siglo esta racionalidad se ha hecho más definida y preponderante. Sin embargo, a mi juicio, no es sino el despliegue de los presupuestos asumidos siglos antes. 
secularización del mundo donde acontece finalmente el desencantamiento del mundo tras un "proceso de desmagificación"19. Esto permitió y exigió el proceso de exploración racional y de experimentación sobre el mundo y todo lo material, incluida la corporalidad humana y su propia identidad biológica, como sabemos, porque el proceso avanza hasta nuestros días. Esta dinámica cultural e histórica generará un conocimiento que permitirá ser aplicado técnicamente al servicio de los deseos humanos, guiados por la lógica de la utilidad. Todo lo que existe, finalmente, debe ser considerado en tanto en cuanto puede ser sometido, transformado o manipulado, obviando todo valor en sí mismo, y, por tanto, desencantándonos de las cosas.

Por ello, John Stuart Mill señalaba que el imperativo racional de la civilización humana, es decir, toda la ciencia y técnica civilizada (o europea), "equivale a una censura contra la Naturaleza, a una admisión de que esta es imperfecta y de que es la tarea del hombre, y su mérito, el estar siempre tratando de corregirla o mitigarla" ${ }^{20}$. La naturaleza, al ser considerada como lo opuesto a lo humano, como su enemigo, solo es percibida por Mill como fuente de crímenes contra la humanidad. Si la naturaleza es imputada como la gran criminal, se puede entonces entender mejor el hecho de que la acción devastadora que la modernización despliega contra la misma es una lucha hecha "con buena conciencia". Esta modificación y destrucción del medio natural es realizada en aras de fines elevados:

El deber del hombre es cooperar con los bienes benéficos, no mediante la imitación del curso de la naturaleza, sino esforzándose constantemente en alterarlo y haciendo que la parte de la naturaleza sobre la que podemos ejercer algún control vaya estando cada vez en mayor conformidad con un alto nivel de justicia y bondad. ${ }^{21}$

Aquí se muestra la hybris, la soberbia del sujeto moderno frente a la naturaleza. En el fondo, parece que no solo tiene que hacerse viable en el seno natural para poder seguir viviendo, como nos recordaba Ellacuría, sino que más bien tiene que ajustar cuentas con ella ${ }^{22}$, aunque esto pueda resultar finalmente nihilista para la especie humana.

Pero la autoconfianza de la razón moderna en sí misma frente al mundo no solo se proyecta en la dominación de lo natural, sino también en la capacidad

19. M. Weber, "La ciencia como vocación", óp. cit.

20. J. S. Mill, Nature (1874). Citaré por la traducción de C. Mellizo, La Naturaleza, Madrid, 1998, p. 42.

21. Ibíd., p. 90.

22. Parece que el sujeto tiene que desplazar a un Dios creador que no hizo bien su trabajo y tiene él que hacerse nuevamente su creador, y esta vez, desde las cenizas cósmicas crear un mundo ex nihilo. 
de autocorrección de los efectos adversos o colaterales de esa dominación. Se sigue confiando simplemente en que todo este proceso de destrucción puede ser compensado y anulado por el desarrollo del creciente poder de la ciencia y la técnica. La tecnociencia moderna parece no reconocer límites. Esto se presenta como un hecho y no como una proyección ideal. La esencia de la misma podría decirse que radica en su continua aspiración a superar los obstáculos y males físico-naturales, tal y como enfatizó John Stuart Mill. El control del cuerpo, del espacio y recursos naturales, e incluso de los propios desastres sociales y ambientales que pueda ir generando el mismo desarrollo moderno, se confía al progresivo avance tecnocientífico que permita corregir las disfunciones que va generando y superar los límites que se van encontrando. En este sentido, la técnica moderna parece, por fin, ser la escalera que nos permitirá llegar al cielo de los anhelos de perfección humana. Sin embargo, a partir de la imagen de cuasiomnipotencia que se desprende hoy de la tecnología, y particularmente de la biotecnología, no puede considerarse con la capacidad, mediante su único dinamismo, para anular los efectos devastadores que nuestra civilización moderna está generando sobre la naturaleza.

\section{La crisis de la civilización moderna}

Hoy estamos de lleno en la crisis humana y ecológica que este horizonte cultural moderno provoca, pero esta crisis también revierte finalmente en una crisis del mismo horizonte. De algún modo, la "ferocidad predatoria" 23 de la que hablaba Ellacuría como dinamismo fundamental de la civilización occidental moderna, también es una autoamenaza. Por eso, señalaba Ellacuría que tenía un carácter inhumano, al basarse en un continuo proceso de exclusión de las mayorías del planeta y del propio mundo natural, que lo hacía ser inviable humanamente por su carencia de sostenibilidad o de universalización material y social. En los tiempos posmetafísicos y posmodernos que vivimos, que parecen más bien la culminación de una modernidad con unas altas dosis de violencia en sus resultados prácticos, el paradigma de la guerra parece constituirse en la mayor certeza. En el plano de las realizaciones de la razón práctica hegemónica, se actúa desde el postulado de que la dominación, en última instancia la muerte del otro/lo otro, es la garantía de la vida de uno. Esta es la mayor seguridad metafísica de nuestro tiempo sociohistórico. Domina, o serás dominado.

En este contexto, este horizonte del sujeto como realidad primaria y última, si es el lugar o ámbito desde el que entender la interacción entre el ser humano y las instancias con las que hace su vida, es un lugar que se nos presenta como proble-

23. I. Ellacuría, "Utopía y profetismo" (1990), en I. Ellacuría y J. Sobrino (eds.), Mysterium liberationis. Conceptos fundamentales de la Teología de la Liberación, Madrid-San Salvador, 1990. 
mático y del que tenemos que salir o resituarnos. En este sentido, la crisis que Occidente está globalizando por el mundo puede ser vista como una "necesidad" cultural, como una función de la renuncia que Occidente se autoimpuso desde la modernidad por su propio marco de verdad y de realidad, con su reducción antropocéntrica bajo la centralidad del individuo. Pero esta civilización en crisis todavía se plantea como única alternativa.

Pero, como nos recuerda Ellacuría, la forma de vida occidental tiene graves carencias no solo por sus disfunciones, sino como modelo o ideal social, en sus dimensiones de verdad, justicia y realizabilidad.

Nos decía: "Si el comportamiento y aun el ideal de unos pocos no puede convertirse en comportamiento y en realidad de la mayor parte de la humanidad, no puede decirse que ese comportamiento y ese ideal sea (...) humano" ${ }^{24}$; por tanto, no es plenamente un ideal de humanidad en esas condiciones. Y ello porque ese ideal humano, expresado en la forma de vida occidental, no es universalizable para la mayoría de seres humanos, y, por tanto, el grado de verdad es muy limitado.

En cuanto a la pregunta, no ya por el grado de verdad de lo postulado, sino por su justicia, Ellacuría nos responde que este ideal práctico no es el debido, "porque el estilo de vida propuesto en y por la mecánica de su desarrollo no humaniza, [ni] plenifica" 25 , y más bien se trata de una propuesta que es positivamente injusta porque su dinamismo real es el de la dominación y la "insolidaridad con la mayor parte de los seres humanos y de los pueblos del mundo, especialmente con los más necesitados" ${ }^{26}$. Ello supone, en última instancia, que la forma de vida desde la que se presenta como realizable el ideal no sea moral en cuanto a que no atiende a la exigencia racional de universabilidad del ideal, por cuanto el disfrute de unos pocos se hace a costa de los demás.

En cuanto a la cuestión práctica, esto es, en lo que tiene de ajustado o de desajustado para su realización práctica, este modelo es desajustado porque no es universalizable "materialmente, por cuanto no hay recursos materiales en la tierra para que todos los países alcanzaran el mismo nivel de producción y de consumo, usufructuado por los países llamados ricos, cuya población no alcanza el $25 \%$ de la humanidad" 27 . Los datos, en su globalidad, siguen siendo tristemente correctos.

Los cantos de sirena de la posmodernidad quieren despistarnos de que vivimos tiempos modernos, demasiado modernos. Por eso, el problema de

24. Ibíd., p. 406.

25. Ibíd., p. 407.

26. Ibídem.

27. Ibídem. 
nuestra época no es la afirmación de certezas perdidas, sino de apertura de nuevos sentidos de la historia, y con ello la búsqueda de mejores posibilidades de vida para todos. Un mundo, a pesar del diagnóstico de Nietzsche, más humano y, por ello, más divino.

Señala John Holloway que la lucha revolucionaria es hoy "una lucha contra la reificación y la certeza" ${ }^{28}$. Si Nietzsche nos explica nuestro mundo con su razón cínica, entonces tiene razón Ellacuría, en un sentido más radical, humano y esperanzador: cansados ya de la repetición de la historia de la dominación, hay que "revertir la historia, subvertirla y lanzarla en otra dirección" 29.

En el último siglo, el desarrollo del nivel de vida en contextos primermundistas se ha conseguido gracias a un coste ecológico tal que nuestro nivel de vida actual y nuestro modelo cultural de desarrollo humano se considera inviable para proseguir más allá de las próximas décadas. No damos ya tiempo a la naturaleza para autorregenerarse del impacto negativo sobre ella.

Estamos en un tiempo de desajustes globales que generan los diversos sentidos principales de la crisis actual. Por un lado, la crisis de la exclusión social de millones de personas, y, por otro, la crisis ecológica por el abuso de los recursos naturales y la alteración o destrucción de los ecosistemas en los que se sostenía la vida humana, y que genera a su vez nuevas crisis sociales. Pero estos desajustes que hacen inviable para muchos la vida humana y no humana tienen una fuente cultural o civilizatoria: los diferentes modos de habérselas con los otros y con la naturaleza en cada uno de los ámbitos que definen los procesos sociales actuales de la sociedad mundial. En función de las "externalidades" o de las disfunciones que globalmente genera esta civilización moderna avanzada, o "civilización de la riqueza y el capital" como la denominaba Ellacuría, se puede ver el desajuste del horizonte cultural o civilizatorio actual como fuente de diversos desajustes del mundo actual, por su responsabilidad en el proceso de globalización o de unificación fáctica de las condiciones de vida humana y no humana que se genera en el planeta. Hay y subsisten diversas tradiciones culturales y religiosas de la humanidad (que tiene, a su vez, que enfrentar sus propios desajustes internos o sus opresiones particulares), pero estas tradiciones se configuran en buena medida en sus sistemas de vida desde un patrón cultural o civilizatorio hegemónico, desde el cual luchan por la supremacía los diversos grupos sociales de la humanidad. Estas tradiciones no tienen la fuerza para configurar prácticamente las interacciones jurídicas, económicas, científicas, tecnológicas o ecológicas en el conjunto de la humanidad, sino que se definen

28. J. Holloway, Cambiar el mundo sin tomar el poder. El significado de la revolución hoy, Madrid, 2002, p. 192.

29. I. Ellacuría, "El desafío de las mayorías populares" (1989), en Escritos universitarios, San Salvador, 1999, p. 301. 
por usar los mismos recursos culturales que los países de origen occidental en la lucha por la supremacía.

En este sentido, la crisis de la civilización moderna no se resuelve por la adopción de otras alternativas civilizatorias colonizadas con pretensión hegemónica, sino desde la lucha intercultural por enfrentar los supuestos básicos de la matriz cultural moderna, que hoy es global. En este sentido, la liberación de otro horizonte cultural posmoderno desde las prácticas sociales críticas que se articulan interculturalmente desde diversas tradiciones occidentales y no occidentales tienen en común tratar de enfrentar los límites de la matriz cultural moderna. El mismo Ellacuría era consciente del problematismo y del desajuste, porque lo podía visibilizar ya desde su contexto histórico, de esa matriz que ha configurado con éxito la sociedad global, pero cuyo éxito es también el propio problema. Traigamos a colación su propio análisis:

Al tratar de concretar algunas de las ideologías que mantienen y justifican esta situación nos referimos a aquella visión que limita al hombre a su ser económico (consumidor-productor) y político (ciudadano abstracto disminuido y manipulado), que reduce la naturaleza a simple recurso económico y que relega a Dios a ciertas funciones reguladoras. Este horizonte cultural dominante, cuya matriz explicativa se encuentra en la Ilustración, debe ser juzgado desde sus efectos negativos: Masa de personas excedentes, naturaleza saqueada y destruida, Dios funcionalizado... Y de un modo global, ruptura de relaciones humanizadoras y fundantes. ${ }^{30}$

Esa ruptura de las relaciones humanizadoras y fundantes, en síntesis, expresa los límites de la modernidad y su propia fecundidad histórica.

El desajuste que la actividad humana desde la civilización moderna está generando no puede ser solucionado simplemente desde sus mismos supuestos básicos, sin un cuestionamiento del marco cultural en el que se funda. De algún modo tiene que ser reordenado y reorientado en un nuevo horizonte de intelección, que hoy se presenta como necesidad y que se va construyendo en diversas prácticas críticas contrahegemónicas en la lucha por hacer posible no solo otros mundos en este, sino el mismo mundo en el que quepan otros. Los problemas ecológicos y sociales de nuestra época nos hacen cuestionarnos sobre el problematismo del horizonte de la subjetividad moderna. Nos decía Zubiri que un horizonte cultural entra en crisis cuando las cosas "no encajan bien". Cuando el marco desde el que se entienden y son tratadas se presenta como incapaz de tratarlas debidamente; por tanto, cuando ese ámbito o lugar es visto como la fuente misma del desajuste de las respuestas humanas frente a lo real.

30. I. Ellacuría, "Dimensión ética de la filosofía" (1984), en J. A. Senent y J. Mora (dir.), Ignacio Ellacuría 20 años después. Actas del Congreso Internacional, Sevilla, 2010, p. 493. 
Si el ser humano no es mero trozo del universo, como denunció la modernidad, tampoco es su envolvente virtual, sino que, como avanzó Ellacuría, es ambas cosas en intrínseca codeterminación, aunque ese "ambas cosas" esté por construirse. Habría que considerar el último siglo como aquel donde se ha hecho visible la dificultad de la modernidad para articular las respuestas humanas frente a las exigencias de lo real. En cierto modo, esta conciencia de la crisis es el punto desde el que se gesta el intento de superación de los desajustes presentes. Esta crisis cultural es interior en Occidente, pero no se puede afrontar, a mi juicio, sin una escucha de otras voces que nacen de otros lugares, de otros supuestos culturales negados que interpelan al vigente. Sin embargo, el nuevo horizonte que provea otros ajustes de las acciones humanas con lo real, para nosotros, no parte de cero, sino que tiene que transformar críticamente la modernidad en otro camino de nueva síntesis que no puede ser simplemente un abandono ingenuo e indolente de lo realizado ${ }^{31}$. Se trata, a mi juicio, no ya de contraer el horizonte, como hizo la modernidad con respecto al anterior, sino de un proceso de ampliación al que socialmente estamos abocados, y del que normativamente empezamos a detectar nuevas consecuencias modificando nuestra modo de relación con los otros, lo natural externo y la naturaleza que nos constituye. En este sentido, lo posmoderno de las prácticas críticas reside en la reconstitución de las relaciones humanizadoras y fundantes, lo cual no tiene nada que ver con el "posmodernismo" agotado que opera desde la misma ruptura de relaciones que estableció la modernidad.

\section{Qué idea de universidad en Ignacio Ellacuría}

Ya hemos apuntado al principio que la idea ellacuriana tenía un cierto carácter contracultural con respecto al ejercicio de racionalidad científica que sintetizó Weber como propio de la ciencias empíricas, sean naturales o sociales. Si Weber nos ofrece una fundamentación de la praxis científica y universitaria moderna desde un ejercicio de la razón que se declara irresponsable de la marcha de lo real, como un observador o notificador de la objetividad del mundo humano y no humano, Ellacuría, en la senda de muchos esfuerzos críticos, rompe con ese mito de la irresponsabilidad ${ }^{32}$ afirmando la corresponsabilidad en la marcha de lo

31. Como señala Ellacuría, la necesidad de "comenzar de nuevo", de imprimir un nuevo rumbo a la marcha de la humanidad que se oriente por la superación de los desajustes civilizatorios presentes, no consiste sin más en "comenzar de nada"; en "El desafío de la mayorías populares", óp. cit., pp. 299-330.

32. Recordemos, en este contexto, las palabras de Franz J. Hinkelammert, sobre la universidad y la cultura de la responsabilidad: "Enfrentar las amenazas globales es ciertamente un problema político. Pero no se reduce a eso. La universidad no es una instancia política y no tiene que llevar a cabo esas políticas necesarias. Pero este enfrentamiento tiene dimensiones que van mucho más allá de la dimensión política. Toda nuestra cultura y civilización están involucradas. No se puede enfrentar las 
real de la praxis científica y universitaria, fundamentada en otra comprensión de la verdad, histórica y éticamente tensionada ${ }^{33}$.

Así, Ellacuría, cuando piensa y trata de articular la misión universitaria de otro modo, proyecta una "universidad distinta" 34 , como para él era y debía ser la Universidad Centroamericana "José Simeón Cañas", de El Salvador, en la que concretó su compromiso y otro modo de hacer universidad. Esta, por su contexto latinoamericano, atravesado por la injusticia estructural, y por su inspiración cristiana, tenía que asumir otro modo de responder universitariamente. Pero ello, en el fondo, dados los desafíos globales de la humanidad, la interdependencia y las responsabilidades en las situaciones estructurales del conjunto de la humanidad de cualquier actor institucional, y máxime desde su mayor poder y posibilidad de incidencia, es hoy lo necesario para cualquier universidad que quiera estar a la altura de su misión histórica, aun cuando su concreta estructuración deba estar definida desde las necesidades de su contexto.

Por ello, una universidad "distinta" no es solo centro de investigación de la realidad y centro de educación superior de las verdades poseídas por la investigación, sino que tiene una tarea ética desde sí misma frente a la realidad: para la liberación, la transformación o el cambio social. Pero esta tarea, de incidencia política o práctica, no debe nunca dejar de ser "universitaria", para Ellacuría. Para él, la universidad también es el conjunto de las ciencias y del saber, pero se trata de un esfuerzo teórico por saber y por posibilitar un hacer desde ese saber:

La forma específica con que la universidad debe ponerse al servicio inmediato de todos es dirigiendo su atención, sus esfuerzos y su funcionamiento al estudio de aquellas estructuras que, por ser estructuras, condicionan para bien o para mal la vida de todos los ciudadanos. Debe analizarlas críticamente,

amenazas globales sin desarrollar una cultura que permita y empuje hacia la responsabilidad en relación con estas amenazas globales. Sin embargo, no se puede empujar hacia la responsabilidad sino en el ámbito de una gran esperanza. Responsabilidad presupone esta esperanza. Si nos damos cuenta de eso, aparece una función clave, cuyo cumplimiento no compete exclusivamente a la universidad, pero depende en parte importante de ella. La universidad es un lugar clave en nuestra sociedad donde es formulada y desarrollada nuestra cultura. La función que aparece es la de la promoción de una cultura que sea cultura de la responsabilidad basada en una cultura de la esperanza"; en "La universidad frente a la globalización", en El sujeto y la ley. El retorno del sujeto reprimido, Heredia, 2003, pp. 369-370.

33. "La verdad, a su vez, no es total hasta que muestre su capacidad operativa, su capacidad de hacer justicia"; en I. Ellacuría, "Discurso de la Universidad Centroamericana 'José Simeón Cañas' en la firma del contrato con el Banco Interamericano de Desarrollo (BID)" (1971), en Escritos universitarios, óp. cit., p. 25.

34. $C f$. I. Ellacuría, "Diez años después, ¿es posible una universidad distinta" (1975), en Escritos universitarios, óp. cit., pp. 49-92. 
debe contribuir universitariamente a la denuncia y destrucción de las injusticias, debe crear modelos nuevos para que la sociedad (...) pueda ponerlas en marcha. ${ }^{35}$

Así, la universidad en su servicio a la sociedad asume también, si es que se sitúa en el plano de la afirmación potenciadora y no en el de la mera reproducción, una tarea crítica y creadora.

Si esto es así, ¿dónde queda la dimensión de verdad como misión esencial desde la que debe definirse la universidad? Nos dice Ellacuría que "la universidad debe ser, ciertamente, un laboratorio de la verdad. Pero la verdad no solo se encuentra, también se hace. Más aún, la verdad encontrada debe ser una verdad operativa, aunque sin olvidar que la acción para hacer realidad la verdad debe ser ella misma verdadera, es decir, no ajena al menester intelectual. Esta totalidad de verdad y realización es la que justifica el sentido universitario" ${ }^{36}$ de la incidencia social.

Por tanto, junto al carácter de una búsqueda de la verdad objetiva y técnica, como clarificación de los procesos sociales, hay un indisociable carácter ético, puesto que la verdad no es puramente lo dado, simple objetividad, sino que apunta en su misma estructura a otras posibilidades de lo real, de ahí que incluya la dimensión de lo que puede y debe ser hecho ${ }^{37}$. En este sentido, tiene la búsqueda de la verdad también una dimensión de justicia que no es simplemente cuestión de probidad científica, sino que arraiga en su carácter realizativo; no es solo la verdad de lo que se da, sino de lo que puede darse en la mutua implicación entre inteligencia y realidad. La verdad no es solo factum, sino un faciendum, un hacerse dinámico; por eso, es histórica y nos permite y exige la opcionalidad como algo constitutivo de la razón humana. Y por eso este faciendum puede apuntar, si nos decantamos opcional y éticamente hacia el polo de la afirmación, hacia la liberación de todos. No se aquieta en lo dado como algo estático, sino

35. I. Ellacuría, "Discurso de la Universidad Centroamericana", óp. cit., p. 22.

36. Ibíd., p. 23. En esta línea, es la búsqueda de la verdad desde la que se define el quehacer universitario, pero se trata de una "verdad social, que sea el encuentro y realización de lo que a todos es debido. De ahí que entienda como su principal misión ser conciencia crítica y creadora de la realidad (...) Sobre esa realidad debe orientar su propia planeación. No pretendemos ser activistas, pero sí exigimos para nosotros aquella autonomía en el pensamiento y en la comunicación, que nos permita el acceso a toda fuente de verdad, que nos permita comunicarla, que nos permita aquella forma sublime de acción que es el pensamiento, que en la justicia construye libertad"; ibíd., p. 24.

37. He analizado con más detalle esta cuestión del carácter abierto y ético del conocimiento en el juego de la acción humana a partir del análisis ellacuriano, en "El problema del ajuste y desajuste: hacia una nueva dimensión de lo normativo", en Ignacio Ellacuría 20 años después, óp. cit., pp. 243-248. 
que puede avanzar en una elección consciente y crítica de una meta social que adquiere razonabilidad en función de la vida humana y no humana que permite. Por tanto, no es una tarea de sustitución o anulación de la libertad y responsabilidad de los otros, sino que se trata de una tarea mayéutica, que ayuda a dar a luz, que colabora desde los saberes en la promoción de los caminos para alcanzar la libertad, y, a su vez, para seguir sosteniendo la posibilidad radical de seguir construyendo la historia. Junto al análisis crítico de lo que hay, y del dinamismo en que está inscrito, se proyecta así la tarea creativa y propositiva de otro marco cultural que apure nuevamente unas mejores posibilidades desde otro principio fundante para la inserción en el mundo de la praxis científica y universitaria.

Por ello, el universitario o el científico no puede solo contemplar desde fuera los procesos naturales, sociales o personales, sino que tiene una corresponsabilidad en la plenificación de esos procesos.

De ahí que el científico, el universitario, o la universidad como un todo, no se encuentren en una cómoda (o triste) neutralidad ante los procesos que simplemente describen o explican. Solía decir Ellacuría que era libremente parcial hacia la causa de los pobres. En la parcialidad hacia lo que está siendo negado e impedido en su pleno despliegue de lo que podría ser para que llegara a ser lo que debía, hay una opción teórica radical que nace de otro principio constitutivo del marco de acción científico-universitario. En el ejercicio de la libertad científica o universitaria hay un decantamiento, o no, por la superación de la negatividad de la realidad, y máxime en la realidad humana. En la estructura de cada situación histórica en que se desarrolla el quehacer universitario, o se toma partido activamente por su superación, o sin tomarlo ya se ha hecho una opción por su continuidad. Por ello, la postura ellacuriana se mueve reflexiva y éticamente en el conjunto de los muchos esfuerzos críticos que señalan los límites de la racionalidad científica clásica y en la necesidad de ampliar el horizonte o marco de realidad y verdad desde donde operan la ciencia y la universidad modernas.

En el contexto de nuestra realidad histórica de hoy, la misión, al tener un carácter radicalmente histórico por ser primariamente actividad humana, implica y supone la articulación del conocimiento y de saberes con aquella realidad histórica que se quiere "iluminar y transformar" 38 . Si esta ha alcanzado un carácter global, la lucha histórica y ética en que se inscribe la acción universitaria sería, a nuestro juicio, la producción de otro mundo que supere las amenazas y la negatividad del presente, "por medio del análisis racional de la situación y el esfuerzo creativo por encontrar su remedio" 39 . En ese análisis racional entran la escucha de los procesos sociales no simplemente como objetos posibles, sino

38. I. Ellacuría, "Discurso de graduación en la Universidad de Santa Clara" (1982), en Escritos universitarios, óp. cit., p. 224.

39. Ibídem. 
también con su propia articulación, con su ser y saber negado, despojado a veces. Por ello, es un saber que ilumina con y desde los otros sujetos del proceso, y, por tanto, en diálogo con ellos.

Para ello, creo que debemos andar hacia la práctica de lo que Boaventura de Sousa Santos denomina una "ecología de saberes". La cual implica una profundización de la investigación-acción que supone una "revolución epistemológica" en el seno de la universidad. La ecología de saberes consiste en la promoción de diálogos entre el saber científico y humanístico, que la universidad produce, y los saberes populares, tradicionales o de otras culturas, que circulan en la sociedad ${ }^{40}$. Como es el caso de las culturas indígenas o campesinas, pero también en los países centrales, donde "otros conocimientos, filosóficos, de sentido común, éticos e inclusive religiosos" ${ }^{41}$ comienzan a incluirse en el debate en el espacio público ofreciendo otras orientaciones sobre los procesos sociales. En esta línea, debemos señalar que, a nuestro juicio, Ellacuría puso en marcha esa "ecología de saberes" al situarse desde su matriz cristiana en diálogo con la ciencia y el pensamiento moderno, pero también desde el contexto histórico y cultural centroamericano. Desde ahí, articuló una praxis universitaria, donde en particular la "inspiración cristiana" tenía para él una especial fecundidad para dicha actividad $^{42}$, pero no por "cristianizar" confesionalmente la universidad, sino por

40. "Junto a la euforia tecnológica ocurre hoy una situación de falta de confianza epistemológica en la ciencia, derivada de la creciente visibilidad de las consecuencias perversas de algunos progresos científicos y del hecho de que muchas de las promesas de la ciencia moderna todavía no se han cumplido (...) la universidad, al especializarse en el conocimiento científico y al considerarlo como la única forma de conocimiento válido, contribuyó activamente a la descalificación e inclusive a la destrucción de mucho conocimiento no científico y con eso, contribuyó a la marginación de los grupos sociales que disponían de esas formas de conocimiento. Es decir, que la injusticia social contiene en su seno una injusticia cognitiva”; en B. S. Santos, La universidad en el siglo XXI. Para una reforma democrática y emancipadora de la universidad, Buenos Aires, 2005, p. 57.

41. Ibídem.

42. "El cristianismo, realmente entendido, defiende y promueve una serie de valores fundamentales que son esenciales para nuestro proceso histórico y, por lo tanto, de gran servicio para una labor universitaria comprometida con el proceso histórico. Ve en los más necesitados, de una forma o de otra, a los redentores de la historia, a los privilegiados del reino de Dios, en oposición a los privilegiados de este mundo, propugna la negación de elementos deshumanizadores como son el ansia de riqueza, de honores, de poder, el halago de los poderosos de este mundo; propugna la sustitución del egoísmo por el amor como motor de la vida humana y de la historia y pone el centro de interés en el otro, en la entrega a los demás, más que en la exigencia de los otros; quiere más servir que ser servido; promueve el rechazo de las desigualdades injustas; afirma el valor trascendente de la vida humana, el valor de la persona, vista desde el Hijo de Dios y, consiguientemente, la solidaridad y fraternidad entre todos los 
estar efectivamente enraizada en una experiencia que le posibilitó otro modo de hacer ciencia y universidad.

\section{La matriz cristiana e ignaciana de la visión ellacuriana de la misión universitaria: "Hagamos redención del género humano"}

En la línea señalada anteriormente, cabría destacar, pues, que en la redefinición y ampliación de lo que debe entenderse como acción científica y universitaria, jugó un papel central su experiencia cristiana en el seno de la tradición ignaciana. Si hacemos una síntesis de ello, diría que el motor de su praxis universitaria arranca de un modo de ver, sentir y estar en la realidad no de carácter solo contemplativo y clarividente de los destinos de los procesos sociales, sino responsablemente compasivo y liberador: frente al puro conocimiento de la continuidad de la negatividad, surge la dinámica central del "hagamos redención del género humano" ${ }^{43}$. La misión universitaria, para Ellacuría, es una síntesis del modo de vida teorético y del modo de vida ético arraigado en una tradición espiritual que le permite hacer esa síntesis.

Por ello, sobre el carácter cristiano de su acción universitaria, nos puede decir:

Una universidad de inspiración cristiana no puede tener duda sobre el partido que ha de tomar. No siendo posible, en un determinado momento histórico, la superación anuladora de las diferencias, tiene que ponerse de parte de aquellos sectores, que no solo son la mayoría, una mayoría tan aplastante, que ya solo por esta razón cuantitativa puede considerarse como la auténtica representativa de los intereses generales, sino que son la mayoría injustamente deshumanizada. En este sentido, no pueden ser las clases dominantes el criterio de su orientación, sino los intereses objetivos, científicamente procesados, de las mayorías oprimidas. ${ }^{44}$

Esta era, por tanto, una forma de poner a producir esa matriz cristiana. Ello implica otro sujeto que labora con la verdad, que pone en marcha un modelo de

hombres; despierta la necesidad de un futuro siempre mayor y desata así la esperanza activa de quienes quieren hacer un mundo más justo en el que, por lo mismo, Dios puede mostrarse más plenamente; ve en la negación del hombre y de la fraternidad humana la negación radical de Dios y, en este sentido, del principio de toda realidad y realización humana... Como todos esos valores no son puras confesiones ideales, sino exigencias fundamentales que han de ser vividas y ejecutadas, la presencia de la inspiración cristiana, sin necesidad de muchas confesiones explícitas, es un principio potenciador del trabajo universitario"; en "Diez años después” óp. cit., pp. 91-92.

43. I. de Loyola, Ejercicios espirituales, n. ${ }^{\circ}$ 107, en Obras de san Ignacio de Loyola, Madrid, 1997, p. 249.

44. I. Ellacuría, "Diez años después, ¿es posible una universidad distinta" (1975), en Escritos universitarios, óp. cit., pp. 54-55. 
racionalidad que "trasciende el análisis". Es decir, no se trata solo de un ejercicio intelectual el que se pide, sino en última instancia de un ejercicio vital y por ello integral. No se trata solo de llevar una vida intelectual (bios theoretikós), sino una vida ética (bios ethicós), donde se pone en juego no solo una forma de pensar o de conocimiento, sino una forma de estar, de hacerse y de responder a la realidad. Ello implica ya un modelo que trasciende el análisis de la fría lógica de la racionalidad científica moderna, donde el sujeto no está implicado en el objeto y ni siquiera se realiza como sujeto, porque al carecer de extensión no pertenece al mundo, como nos diría Descartes en los inicios de la constitución de la ciencia empírica moderna.

Esto exige sujetos no desintegrados, sino que han sido capaces de hacer, ya desde sí mismos, la síntesis compleja que permite responder con seriedad y radicalidad a las carencias de la cultura actual, sujetos que aúnan fe, cultura y sensibilidad: "Fe sólida y profunda, de cultura seria y de auténtica sensibilidad humana y social" 45 ; que reúnen "ciencia y virtud", dos elementos disociados en la racionalidad moderna, uno en el espacio público y el otro en su caso en el privado, y que exigen articular cultura y responsabilidad.

¿Desde dónde se nutre ese trabajo? Ello nos remite a la "fuente de su espiritualidad". En particular, en la tradición ignaciana se nutre de la experiencia configuradora de los Ejercicios espirituales de Ignacio de Loyola, como fuente de su sensibilidad humana y social. Y ello porque los ejercicios no son en primer término una forma de indoctrinamiento (aunque impliquen algunas doctrinas) ni de proyección de una cultura sobre otra, sino un método de trabajo con la sensibilidad y la afectividad, que supone una "reconversión libidinal" 46 , y que desde ahí va posibilitando al sujeto la creatividad para desarrollar otros modos de responder a la realidad y en su caso confrontarse con otras respuestas. Es una experiencia interior que no queda encapsulada, no es simple illusio, o creencia, puesto que si va conformando la subjetividad, lo lanza por su propia dinámica a concretar determinaciones exteriores desde sus acciones: "En la disposición de su vida" ${ }^{47}$. Por tanto, los ejercicios, en su creatividad externa, son generadores no de "conocimiento", sino de otra forma de vida y suponen, en este sentido, una matriz cultural. "Matriz cultural", aquí, es sinónimo de proceso civilizatorio, porque lanza a recrear todos los modos de vida en que se concreta la vida humana y social. Por tanto, no es un asunto solo de formas de pensar, valores, creencias, narraciones..., sino que incluye las dimensiones simbólicas e intelectuales, pero no se acaba en ellas sin recrear las otras dimensiones de las

45. Benedicto XVI en "Alocución a la Congregación General 35 de la Compañía de Jesús", en Congregación General 35 de la Compañía de Jesús, Roma 2008.

46. C. Domínguez Morano, Psicodinámica de los ejercicios ignacianos, Sal TerraeMensajero, 2003, p. 43.

47. I. de Loyola, Ejercicios espirituales, óp. cit., n. ${ }^{\circ} 1,4$. 
prácticas sociales. Si no fuera así, entonces, no podría generar otras estructuras sociales. Se trata de que, desde esa matriz, el sujeto renovado en ella (desde otras habitudes o modos de enfrentarse a las cosas), vive ya desde otros supuestos las diversas dimensiones de vida social. Esto le abre a la lucha por la generación de nuevas estructuras o modos sociales de habérselas con lo político, lo económico, lo social, lo religioso, lo jurídico, lo natural...

En este sentido, se pueden generar sujetos "contraculturales", como nos muestra el caso de Ellacuría y sus compañeros, y de tantos otros, en la medida en que no se adaptan a reproducir el modo existente de vivir esos ámbitos, y luchan por abrir y consolidar otras formas de relación o participación en el poder (estructura política), en la iglesia y frente a otras religiones (campo religioso e interreligioso), de relacionarse con los bienes materiales (economía), con las leyes (campo jurídico), la naturaleza, con los otros del cuerpo social (estructura social), con la ciencia y la educación (generación y socialización del conocimiento social), otros pueblos y culturas (relaciones intersociales e interétnicas). Esto produce, a veces, pequeñas experiencias sociales que "apuntan a otro mundo", otra tendencia plural con respecto a la dirección principal que llevó o lleva la sociedad moderna ${ }^{48}$.

Por ello, la virtualidad práctica de esta fuente espiritual no consiste en una fuga mundi. Como señala Carlos Domínguez, para Ignacio "la experiencia religiosa debe tener una repercusión decisiva en la configuración de la vida (en la disposición de su vida)". No puede quedar reducida interiormente, en última instancia, como mera ilusión, como una experiencia imaginaria. Así, aunque pueda llegar a darse ${ }^{49}$, no se trata de la "creación de un mundo afectivo que

48. Otras fueron grandes experiencias en el sentido en que generaron "otros mundos", es decir, otras estructuras sociales, como pudo ser la experiencia de las reducciones en América Latina, distintas al modo hegemónico en que se articuló a las relaciones intersociales e interétnicas en la primera modernidad.

49. Recordemos aquí que Ignacio de Loyola, hombre de mucha experiencia espiritual, un "místico", como ha sido reconocido en el siglo XX, tenía a su vez un fuerte sentido crítico y de sospecha frente a la pura o mera práctica mística cuando no conforma de hecho a la persona, y lo sitúa de un modo nuevo en su praxis de seguimiento. Así, una cita obligada es la del P. Gonçalves da Câmara en su Memorial sobre dichos y hechos de Ignacio de Loyola, cuando comenta lo siguiente: “(A) un verdaderamente mortificado bástale un cuarto de hora para se unir a Dios en oración'. Y no sé si entonces añadió sobre este mismo tema lo que le oímos decir otras muchas veces: que de cien personas muy dadas a la oración, noventa serían ilusas. Y de esto me acuerdo muy claramente, aunque dudo si decía noventa y nueve" (B. Hernández Montes [ed.], Recuerdos ignacianos. Memorial de Luis Gonçalves da Câmara, Mensajero-Sal Terrae, Bilbao-Santander, 1992, p. 149 [n. ${ }^{\circ}$ 196]). Sobre esto se puede ver A. M. Chércoles, "La oración en los ejercicios espirituales de san Ignacio de Loyola”, Cuadernos EIDES, n. ${ }^{\circ}$ 49, julio de 2007. 
tan solo busca huir del enfrentamiento con la realidad, o, dicho de otra manera, reducido a un mundo fantasmático apartado de lo real, de lo intersubjetivo y, por tanto, no relativizado por el enfrentamiento con ningún tipo de límite" ${ }^{50}$. Si la experiencia va conformando las estructuras psíquicas de la persona, entonces le remite a su propia responsabilidad de estar e incidir en el mundo desde un horizonte de transformación. La persona tendrá que ir creando sus propias respuestas. No es, por tanto, una fuga mundi, sino una generatio mundi, la producción de otro mundo.

De este modo, no es cuestión de meras creencias, o de preferencias axiológicas indiscernibles en sí mismas según la lógica moderna, sino de una formación de la sensibilidad y de las estructuras de la praxis de la persona que se orienta por la praxis de Jesús de Nazaret, y que lo dota de relevancia pública y transformadora en el seno del conjunto de las prácticas científicas, universitarias y sociales.

Por ello, "el caso Ellacuría" revela una validez que puede ser reconocida por gentes de diversas tradiciones y creencias, puesto que generó una praxis crítica que se suma a los esfuerzos de la humanidad por subvertir la historia, y, en ese sentido, su razón crítica, universitaria y cristiana se hace "razonable" para muchos.

Eskerrik asko.

50. C. Domínguez Morano, Psicodinámica de los ejercicios ignacianos, óp. cit. 